\title{
Preclinical evaluation of antitumor activity of the proteasome inhibitor MLN2238 (ixazomib) in hepatocellular carcinoma cells
}

\author{
Giuseppa Augello1, Martina Modica', Antonina Azzolina', Roberto Puleio (1)², Giovanni Cassata², Maria Rita Emma', \\ Caterina Di Sano', Antonella Cusimano' ${ }^{1}$ Giuseppe Montalto ${ }^{1,3}$ and Melchiorre Cervello'
}

\begin{abstract}
Hepatocellular carcinoma (HCC) is one of the common malignancies and is an increasingly important cause of cancer death worldwide. Surgery, chemotherapy, and radiation therapy extend the 5-year survival limit in HCC patients by only $6 \%$. Therefore, there is a need to develop new therapeutic approaches for the treatment of this disease. The orally bioavailable proteasome inhibitor MLN2238 (ixazomib) has been demonstrated to have anticancer activity. In the present study, we investigated the preclinical therapeutic efficacy of MLN2238 in HCC cells through in vitro and in vivo models, and examined its molecular mechanisms of action. MLN2238 inhibited cell viability in human HCC cells HepG2, Hep3B, and SNU475 in a time- and dose-dependent manner. Flow cytometry analysis demonstrated that MLN2238 induced G2/M cell cycle arrest and cellular apoptosis in HCC cells. Cell cycle arrest was associated with increased expression levels of p21 and p27. MLN2238-induced apoptosis was confirmed by caspase-3/7 activation, PARP cleavage and caspase-dependent $\beta$-catenin degradation. In addition, MLN2238 activated ER stress genes in HCC cells and increased the expression of the stress-inducible gene nuclear protein-1. Furthermore, MLN2238 treatment induced upregulation of myeloid cell leukemia-1 (Mcl-1) protein, and MCl-1 knockdown sensitized HCC cells to MLN2238 treatment, suggesting the contribution of Mcl-1 expression to MLN2238 resistance. This result was also confirmed using the novel Mcl-1 small molecule inhibitor A1210477. Association of A1210477 and MLN2238 determined synergistic antitumor effects in HCC cells. Finally, in vivo orally administered MLN2238 suppressed tumor growth of Hep3B cells in xenograft models in nude mice. In conclusion, our results offer hope for a new therapeutic opportunity in the treatment of HCC patients.
\end{abstract}

\section{Introduction}

Hepatocellular carcinoma (HCC) is known to be the second most frequent type of solid tumor ${ }^{1}$. Surgical intervention provides the best response in the early stages of the disease, but this approach is not feasible in all HCC patients. Standard therapy in advanced HCC patients involves the administration of Sorafenib, an oral multi-

\footnotetext{
Correspondence: Melchiorre Cervello (melchiorre.cervello@ibim.cnr.it) ${ }^{1}$ Institute of Biomedicine and Molecular Immunology "Alberto Monroy", National Research Council (CNR), Palermo, Italy

${ }^{2}$ Istituto Zooprofilattico Sperimentale della Sicilia "A. Mirri", Histopathology and Immunohistochemistry Laboratory, Palermo, Italy

Full list of author information is available at the end of the article Edited by R. Johnstone
}

kinase inhibitor, which, unfortunately, has many side effects and increases life expectancy by only 3 months. This has led to the investigation of new treatment strategies and the identification of new target molecules, such as proteasome. Inhibition of proteasome causes an accumulation of misfolded proteins within the cell, an event that triggers the activation of the apoptotic pathway. Bortezomib (Velcade, PS-341), is a first-generation proteasome inhibitor, which the US Food and Drug Administration (FDA) has approved in multiple myeloma ${ }^{2}$ and non-Hodgkin's lymphoma treatment ${ }^{3}$. At the molecular level, bortezomib treatment induces cell death through endoplasmic reticulum (ER) stress induction ${ }^{4-7}$, nuclear 
factor kappa B inhibition ${ }^{8}$, and caspase-8 activation ${ }^{9}$. However, although preclinical results have shown that bortezomib has antitumor effects in $\mathrm{HCC}^{10-12}$, a multicenter single-arm phase II trial conducted in cases of unresectable HCC showed that although bortezomib is well tolerated, it lacks significant activity ${ }^{13}$. Moreover, in many cases patients treated with bortezomib rapidly develop drug resistance, the mechanisms of which are poorly understood ${ }^{14}$.

The good clinical outcome observed with bortezomib in liquid tumor has led to the development of nextgeneration proteasome inhibitors to improve efficacy, avoid pharmaco-resistance and minimize cytotoxicity. Among them, MLN2238 (ixazomib) holds great promise: it is a next-generation reversible proteasome inhibitor, whose main value is that it can be administered orally. MLN2238 is the biologically active form of MLN9708 (ixazomib citrate), which in plasma or after exposure to aqueous solutions quickly hydrolyzes to MLN2238, the biologically active boronic acid. MLN2238 inhibits the 20 $\mathrm{S}$ proteasome chymotrypsin-like proteolytic ( $\beta 5)$ subunit. It has a greater antitumor activity in solid and hematologic tumor models compared to bortezomib ${ }^{15}$. Several studies conducted in multiple myeloma patients have shown that ixazomib has great antitumor effects (NCT00963820; NCT00932698), and therefore the FDA has given its approval for treating this disease, also in association with other drugs, such as lenalidomide and dexamethasone (NCT02389517; NCT02917941) ${ }^{16,17}$. Furthermore, other newer reports have shown that MLN2238 is efficacious in other tumor cell types, such as osteosarcoma $^{18}$, colon adenocarcinoma ${ }^{19}$, melanoma ${ }^{20}$, and neuroblastoma cells ${ }^{21}$. Treatment with MLN2238 results in the stabilization and accumulation of $\mathrm{p} 21^{\text {Waf1/ }}$ Cip122, E2F1 and $\mathrm{p} 53^{18}$, which lead to the activation of caspase-3, -8, -9-dependent cell death pathways, with upregulation of Mcl-1 and NOXA ${ }^{23,24}$.

To date there are no studies on MLN2238 administration in HCC. In this study, we used HCC cells to explore the antitumor effects of MLN2238 in vitro as well as in vivo.

\section{Results}

MLN2238 reduces cell viability and proliferation HCC cells

The impact of MLN2238 on HCC cell viability was assessed by MTS assay. HCC cell lines HepG2, Hep3B and SNU475 were exposed to treatment for 24,48 , and $72 \mathrm{~h}$ with increasing concentrations of MLN2238. As shown in Fig. 1a-c, MLN2238 decreased cell viability depending on the dose and duration of treatment. The various cell lines exhibited differing degrees of sensitivity to MLN2238. At $24 \mathrm{~h}$ of treatment, HepG2 and SNU475 cells exhibited some sensitivity, but the effect did not reach the $\mathrm{IC}_{50}$ value. At 48 and $72 \mathrm{~h}$, all cell lines showed sensitivity to
MLN2238. As shown in Table 1 , at $48 \mathrm{~h}$, the $\mathrm{IC}_{50}$ value for Hep3B cells was $201 \pm 31 \mathrm{nM}$, whereas for HepG2 and SNU475 cells values were $570 \pm 22 \mathrm{nM}$ and $387 \pm 36 \mathrm{nM}$, respectively. At $72 \mathrm{~h}$, the $\mathrm{IC}_{50}$ value for HepG2 cells was $281 \pm 14 \mathrm{nM}$ and the $\mathrm{IC}_{50}$ values for Hep3B and SNU475 were $260 \pm 24 \mathrm{nM}$ and $428 \pm 81 \mathrm{nM}$, respectively.

Furthermore, a BrdU incorporation assay was performed to determine cell proliferation after MLN2238 treatment. Fig. 1d shows that after $48 \mathrm{~h}$ MLN2238 significantly inhibited HCC cell proliferation according to the drug concentration.

In addition, inhibition of proliferation was evidenced by observations using optical microscopy. The images in Fig. 1e clearly show that the number of cells decreased at the various concentrations, and in addition, in HepG2 and SNU475 cells, a typical morphological feature of apoptotic cells was also observed, i.e, cells became rounded and detached from the substrate (Fig. 1e).

\section{MLN2238 induction of G2/M cell cycle arrest and p27 and p21 upregulation in HCC cells}

To clarify MLN2238-induced inhibitory effects on HCC cell proliferation, the cell cycle phase distributions of HepG2, Hep3B, and SNU475 cells were examined by flow cytometry analysis. Fig. 2a shows representative cell cycle phase distributions of the controls and cells treated at 250 and $500 \mathrm{nM}$ MLN2238 concentrations. Quantitative analysis (Fig. 2a, right side) showed that MLN2238 treatment for $24 \mathrm{~h}$ induced a higher cell population in the G2/M phase, and a lower population in the G0/G1 phase than in the control.

Next, to explore the molecular mechanism triggering MLN2238-induced cycle arrest in cells, the expression of proteins involved in controlling G2/M phase cell cycle progression was examined. Treatment with 250 and 500 nM MLN2238 increased expression of the inhibitors of cyclin-dependent kinase p21 and p27 (Fig. 2b).

\section{MLN2238 induces apoptotic cell death in HCC cells}

We further investigated whether MLN2238 elicited apoptotic cell death in HepG2, Hep3B, and SNU475 cells, using flow cytometry analysis. The percentages of early and late apoptotic and necrotic cells increased in comparison with the control according to the doses administered, suggesting that MLN2238 increased cell death in HCC cells (Fig. 3a, b).

Apoptosis induction was also investigated by measuring the activation of caspase-3/7 and analyzing Poly(ADPribose) polymerase (PARP) cleavage. Fig. 3 shows that at $24 \mathrm{~h}$ of treatment an increases in caspase-3/7 activity (Fig. 3c) in all cell lines was observed, whereas PARP cleavage (Fig. 3d) was observed only in HepG2 and SNU475 cells. However, in Hep3B cells PARP cleavage was observed after treatment for $48 \mathrm{~h}$ (Fig. 3d). 

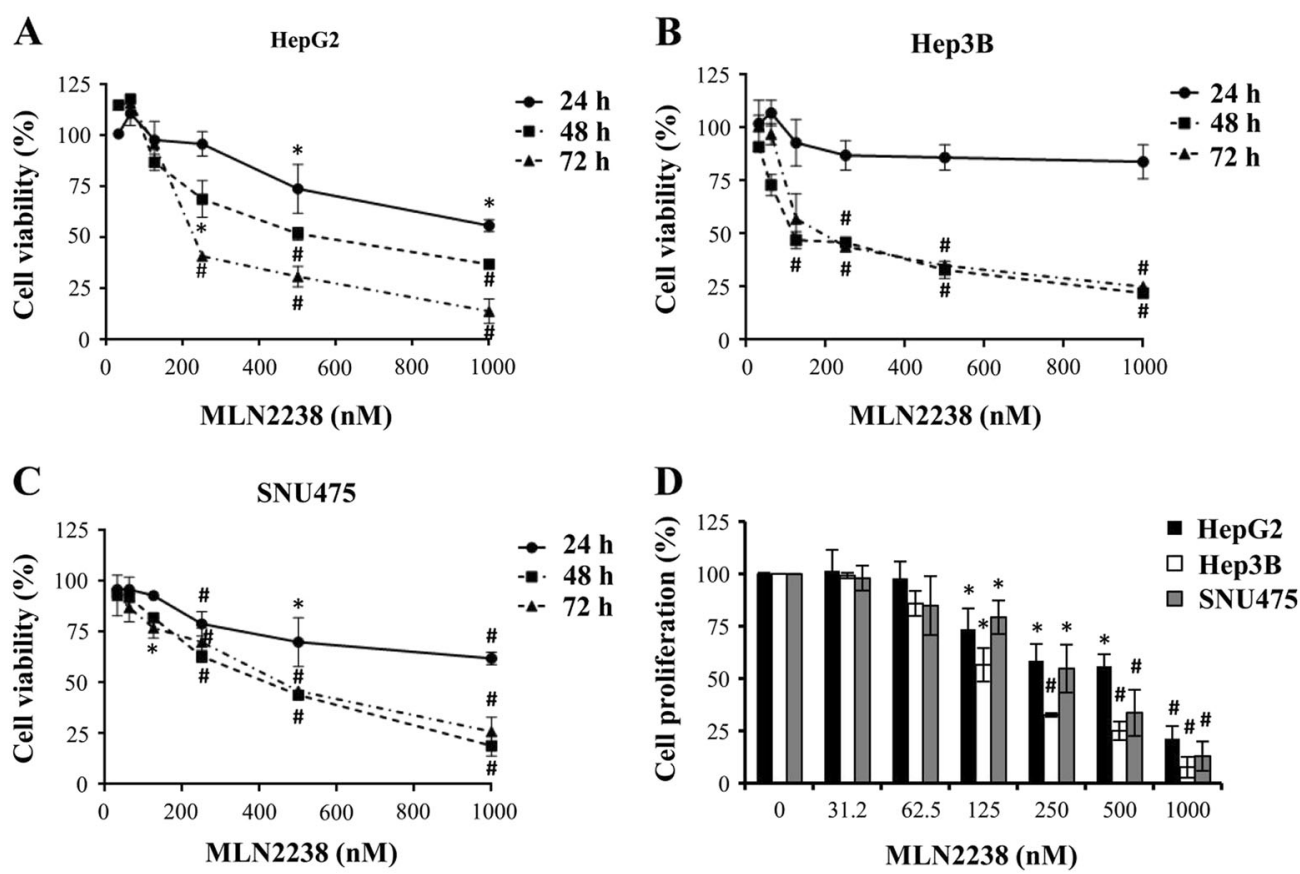

$\mathbf{E}$

HepG2

Hep3B
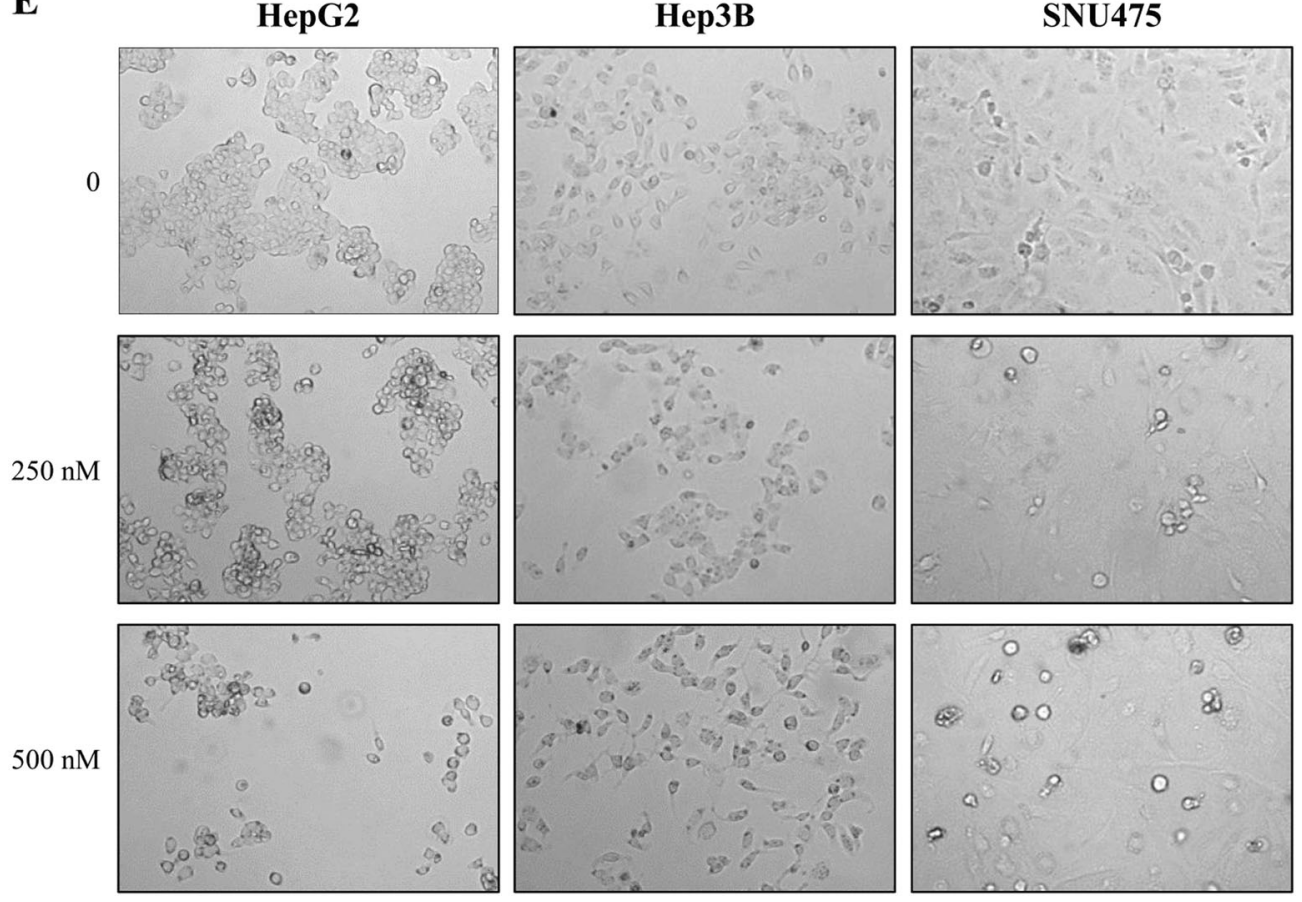

Fig. 1 MLN2238 treatment alters cell viability, proliferation, and morphology in HCC cells. a-c Cell viability was evaluated by MTS assay. HepG2 $\mathbf{a}$, Hep3B b, and SNU475 c cells were treated with increasing MLN2238 concentrations for 24, 48, and 72 h. $\mathbf{d}$ Proliferation was measured by BrdU incorporation into DNA. Cells underwent treatment for $48 \mathrm{~h}$ with increasing MLN2238 concentrations. e Morphological observations of MLN2238-treated cells by phase contrast microscope. Photographs were taken after $24 \mathrm{~h}$ of treatment $\left(\times 20\right.$ magnification). ${ }^{*} P<0.05 \mathrm{MLN} 2238 \mathrm{vs}$. control; " $P<0.005$ MLN2238 vs. control

Proteasome inhibitors have been reported to activate apoptotic response through a specific caspase-dependent cleavage of $\beta$-catenin ${ }^{25}$. Therefore, we analyzed the expression of $\beta$-catenin following MLN2238 treatment. Fig. 3e shows that MLN2238 treatment triggered the cleavage of $\beta$-catenin in HepG2 and SNU475 cells. 
Table $1 \quad I_{50}$ values for MLN2238 in HCC cells

\begin{tabular}{llll}
\hline \multirow{4}{*}{} & \multicolumn{1}{l}{$\mathbf{C}_{\mathbf{5 0}}(\mathrm{nM}$, mean \pm S.D. $)$} & \\
\cline { 2 - 4 } & HepG2 & Hep3B & SNU475 \\
\hline $48 \mathrm{~h}$ & $570 \pm 22$ & $201 \pm 31$ & $387 \pm 36$ \\
$72 \mathrm{~h}$ & $281 \pm 14$ & $260 \pm 24$ & $428 \pm 81$ \\
\hline
\end{tabular}

Furthermore, the involvement of caspases in PARP and $\beta$ catenin cleavage after treatment with MLN2238 was confirmed by using z-VAD-fmk, a cell-permeable and irreversible pan-caspase inhibitor. PARP and $\beta$-catenin cleavage was inhibited by co-treatment with z-VAD-fmk and MLN2238 (Fig. 3e).

The above findings suggest that MLN2238 induced the apoptosis pathway.

\section{MLN2238 induces ER stress}

Several studies have established that proteasome inhibitors, including MLN2238, trigger the unfolded protein response and ER stress ${ }^{4-7,26-28}$. Therefore, we examined the effects of MLN2238 treatment on genes known to be regulated during ER stress response. As shown in Fig. 4, treatment with MLN2238 activated ER stress genes in HCC cells after $24 \mathrm{~h}$. There was an upregulation of the ER stress-regulated genes, including GRP78, ATF4, CHOP and TRB3 (Fig. 4a), and XBP1 mRNA splicing was also induced (Fig. 4b).

In human HCC tissues, we recently observed an overexpression of nuclear protein-1 (NUPR1), a stressinducible protein involved in regulating cell survival, apoptosis, and invasiveness, as well as chemoresistance in $\mathrm{HCC}^{29}$. Therefore, expression levels of NUPR1 were also investigated after MLN2238 treatment. As shown in Fig. 4a, MLN2238 treatment increased NUPR1 mRNA expression in Hep3B and SNU475 cells after $24 \mathrm{~h}$ of treatment. These results confirm that MLN2238 treatment caused the activation of ER stress response in HCC cells.

\section{MLN2238 treatment induces $\mathrm{Mcl}-1$ upregulation}

Numerous studies have demonstrated that proteasome inhibition can trigger the accumulation of myeloid cell leukemia-1 (Mcl-1), which is an anti-apoptotic protein belonging to the Bcl-2 family. To examine whether treatment with MLN2238 promotes the accumulation of Mcl-1 in HCC, HepG2, Hep3B, and SNU475 cells were exposed to 125,250 , and $500 \mathrm{nM}$ of MLN2238 treatment for $24 \mathrm{~h}$ and with $500 \mathrm{nM}$ for 24 and $48 \mathrm{~h}$. Western blot analysis demonstrated that MLN2238 induced Mcl-1 increase in a dose-dependent manner in all HCC cell lines at $24 \mathrm{~h}$ (Fig. 5a), whereas at $48 \mathrm{~h}$, the levels of Mcl-1 decreased in HepG2 and SNU475 cells, and remained higher than the control in Hep3B cells (Fig. 5b).

In addition, we evaluated whether treatment with MLN2238 induced the accumulation of other antiapoptotic proteins. However, western blot analysis of Bcl-2 protein expression demonstrated that MLN2238 induced Bcl-2 downregulation according to the treatment dose and duration (Fig. 5a, b).

Therefore, to explore the relationship between the expression of Mcl-1 and cell susceptibility to MLN2238 treatment, HCC cells were transfected with Mcl-1-specific small interference RNA (siRNA) to inhibit $\mathrm{Mcl}$-1 gene expression. Transfection efficiency after $72 \mathrm{~h}$ of transfection with siMcl-1 was confirmed by a clear reduction in Mcl-1 protein expression levels (Fig. 5c, left side). Furthermore, MTS assays showed that $\mathrm{Mcl}-1$ knockdown (KD) significantly sensitized Hep3B and SNU475 cells to MLN2238 treatment compared with cells transfected with control siRNA (siNC), whereas although a reduction of cell viability was observed in HepG2 cells after $\mathrm{Mcl}-1 \mathrm{KD}$, differences did not reach statistical significance (Fig. 5c, right side). In addition, in Hep3B cells silencing of $\mathrm{Mcl}-1$ promoted MLN2238-induced PARP cleavage and $\beta$ catenin reduction already at $24 \mathrm{~h}$ (Fig. $5 \mathrm{~d}$ ). Overall, these results suggest that on MNL2238 treatment, Mcl-1induced expression protects HCC cells from MLN2238 antitumor effects.

\section{Co-treatment with MLN2238 and Mcl-1 inhibitor \\ A1210477 synergistically reduces cell viability in HCC cells}

To explore the function played by Mcl-1 in MLN2238 resistance in HCC cells, we investigated whether the pharmacological inhibition of Mcl-1 with a potent and specific inhibitor, A1210477, would exert a similar effect to that obtained using the siRNA approach. We thus first determined the dose of A1210477 at which cell viability was minimally affected. At a dose of $10 \mu \mathrm{M}$ A1210477 exerted only minimal effects on cell viability, with $90 \%$, $85 \%$, and $93 \%$ of cell survival in HepG2, Hep3B, and SNU475 cells, respectively (data not shown). Consequently, A1210477 alone $(10 \mu \mathrm{M})$ or in combination with MLN2238 was used for cell treatment. Combinations of the two agents increased treatment efficacy compared with a single agent, as assessed by MTS assay at $24 \mathrm{~h}$ of treatment (Fig. 6). To define the type of interaction between the two agents, the combination index (CI) for each association was determined. As reported in Table 2, according to the CI, a combined treatment with different concentrations of MLN2238 and $10 \mu \mathrm{M}$ A1210477 synergistically inhibited cell viability.

\section{MLN2238 treatment inhibits in vivo tumor growth}

A xenograft tumor model was utilized to demonstrate the antitumor efficacy of MLN2238 on HCC in vivo. 


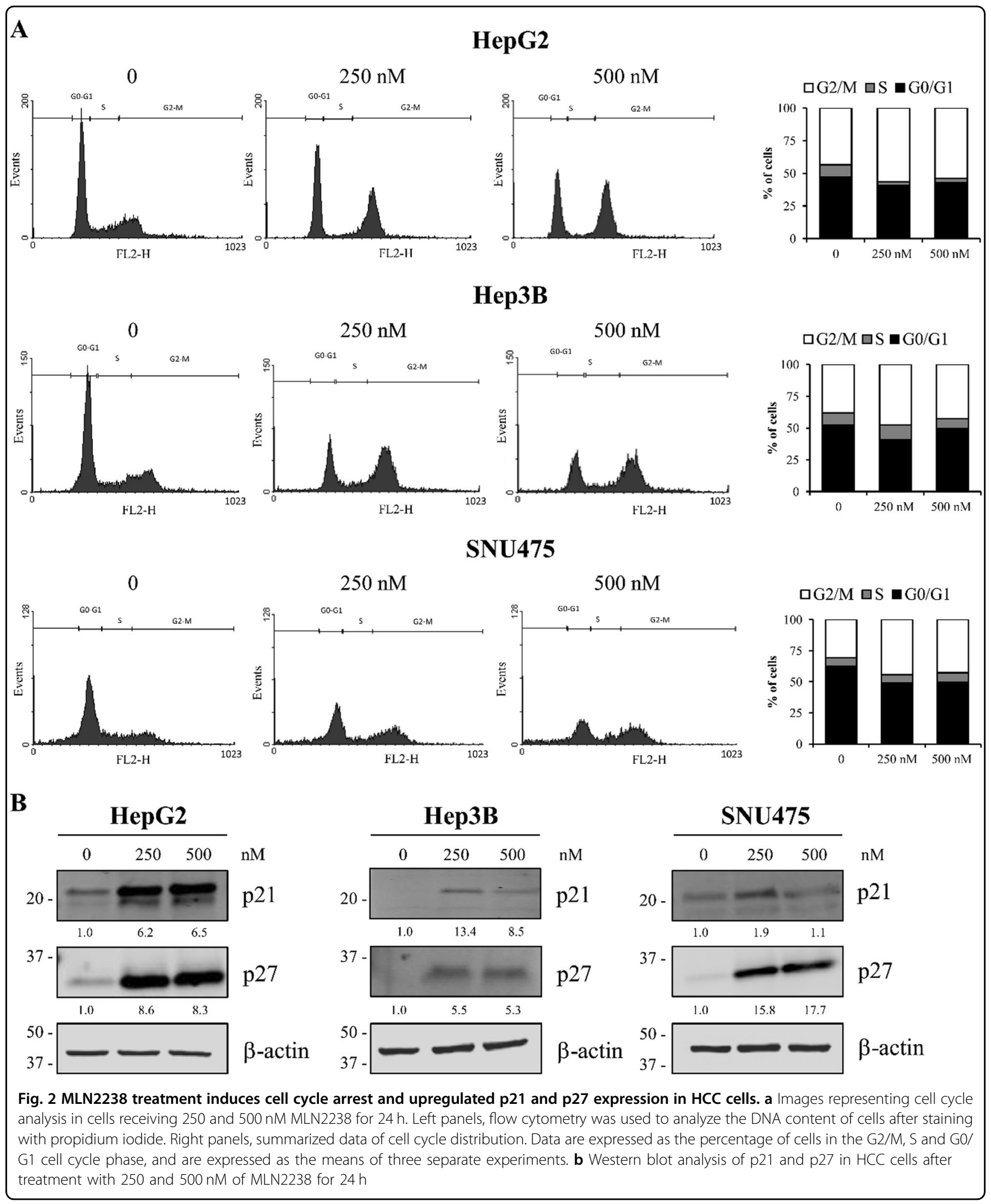

Treatment with MLN2238 led to a significant reduction in tumor volume when compared with the volume measured in the control group (vehicle alone) (Fig. 7a).
Furthermore, drug-associated cytotoxicity was monitored by analyzing changes in the body weight of animals. Treatment of mice with MLN2238 did not significantly 


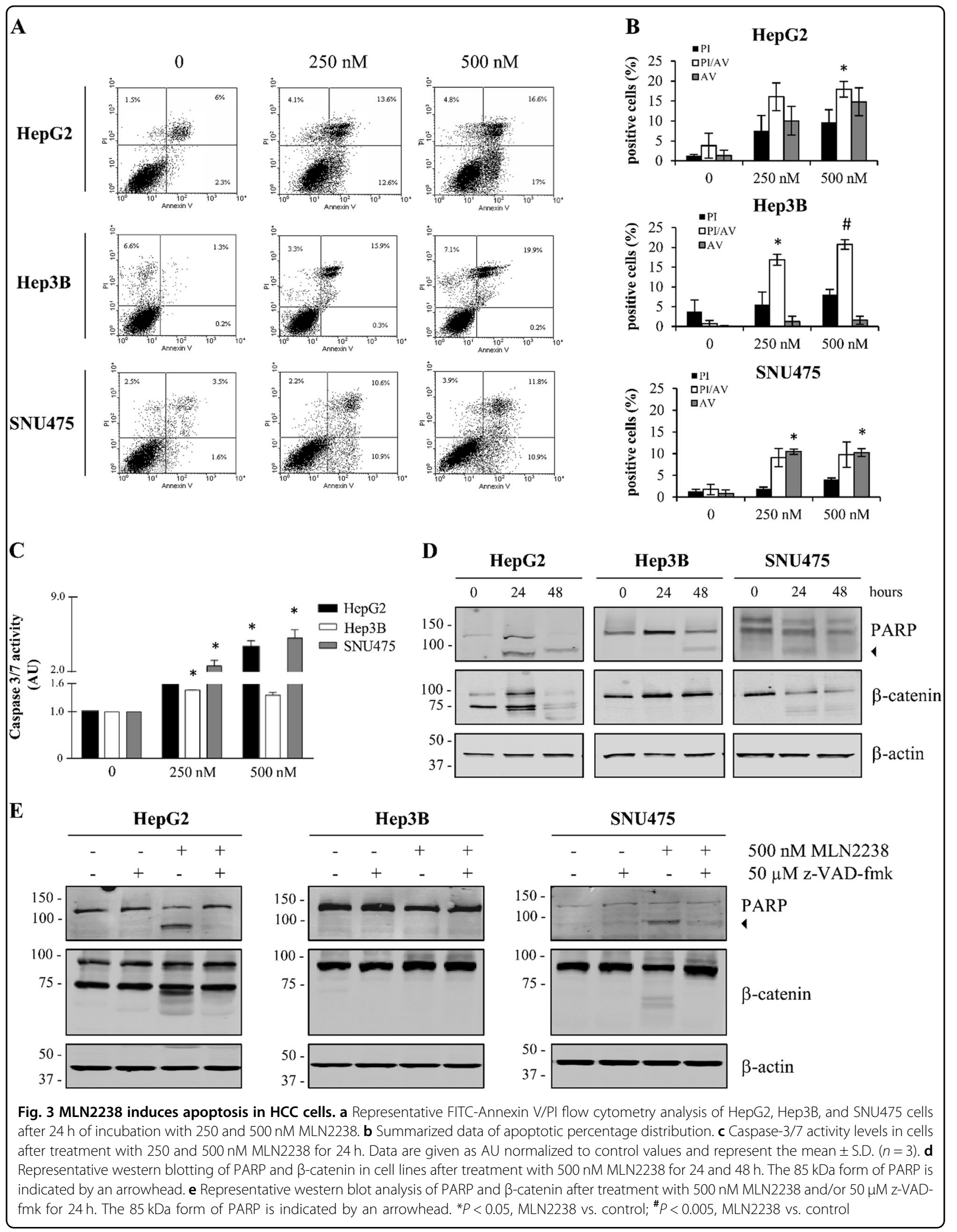




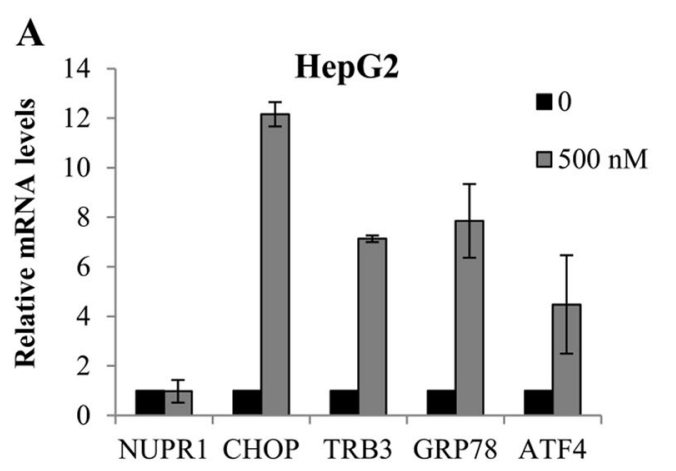

$\mathbf{B}$
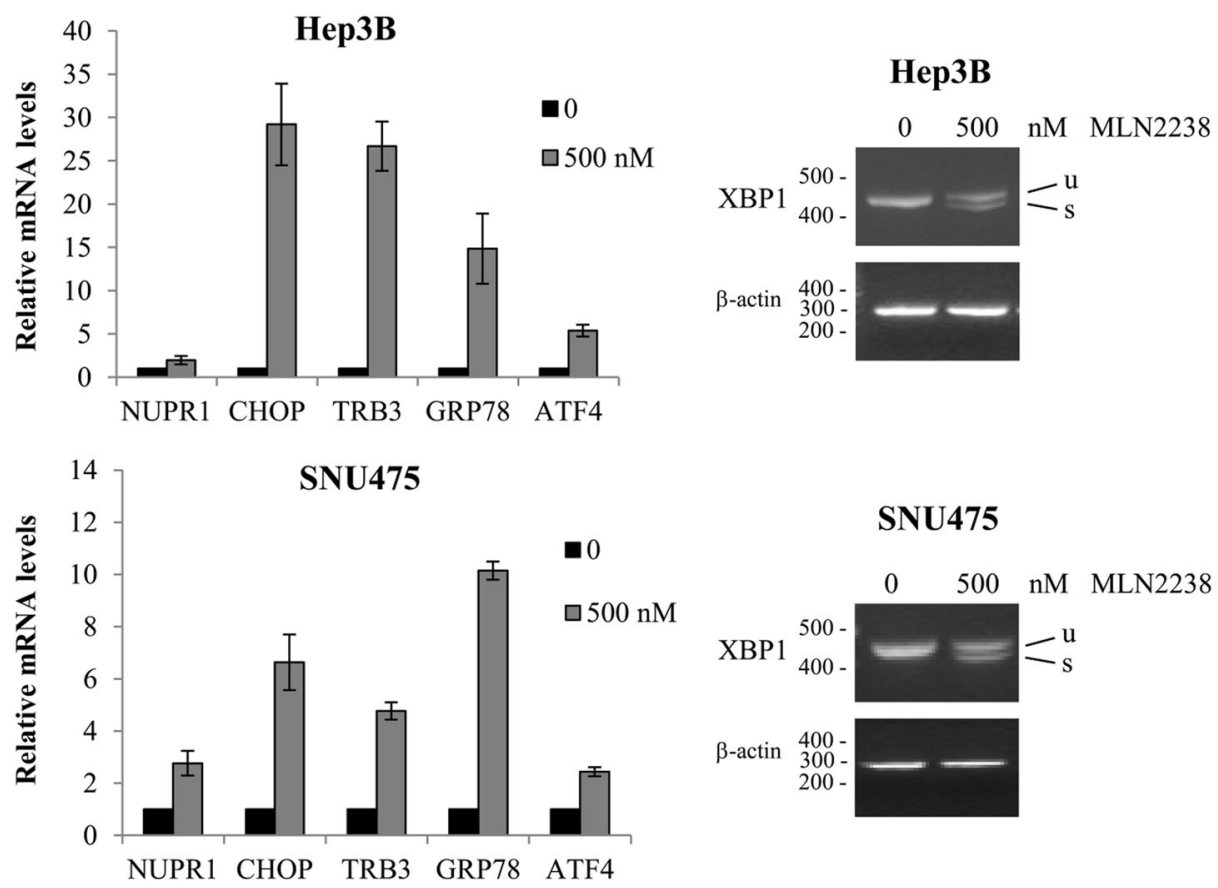

Fig. 4 MLN2238 treatment induces ER stress in HCC cells. Effects of MLN2238 treatment with $500 \mathrm{nM}$ of MLN2238 for $24 \mathrm{~h}$ on ER stress gene expression levels were determined by quantitative Real-Time PCR $\mathbf{a}$ and semiquantitative PCR $\mathbf{b}$. a The relative gene expression was calculated (ratio of drug-treated samples vs. control) and corrected by the quantified level of $\beta$-actin expression. $\mathbf{b}$ Expression of XBP1 mRNA. $u=u n s p l i c e d$ XBP1 mRNA; $s=$ spliced XBP1 mRNA

modify body weight when compared to control group mice, which suggests that drug cytotoxicity was at a tolerable level (Fig. 7b).

To confirm the data observed in vitro, Mcl-1 and p21 expression in tumor tissues in mice receiving MLN2238 was investigated by western blot analysis (Fig. 7c). Mice treated with MLN2238 expressed higher levels of Mcl-1 and p21 than those of mice without the treatment. Therefore, these findings confirmed data previously observed in the in vitro experiments. In addition, histochemical analysis indicated that treatment with MLN2238 inhibited in tumor tissues the expression of Ki-67, a cell proliferation marker (Fig. 7d, e), confirming data obtained in vitro using a cell proliferation assay (bromodeoxyuridine (BrdU) assays).

\section{Discussion}

Proteasome inhibitors represent a new class of promising therapeutic drugs in cancer ${ }^{2,3}$. However, although several preclinical studies have shown that proteasome inhibition by bortezomib could represent a viable therapeutic strategy for treatment of $\mathrm{HCC}^{10-12}$, clinical results obtained in patients with unresectable HCC have been disappointing ${ }^{13}$.

By contrast, the good clinical results observed with bortezomib in other tumor types have led to the development of next-generation proteasome inhibitors, such as MLN2238 (ixazomib) ${ }^{15,22}$, which has demonstrated better pharmacokinetics, pharmacodynamics, and antitumor activity compared with bortezomib ${ }^{15,30}$. Recently, ixazomib was shown to inhibit the in vitro growth of 
A
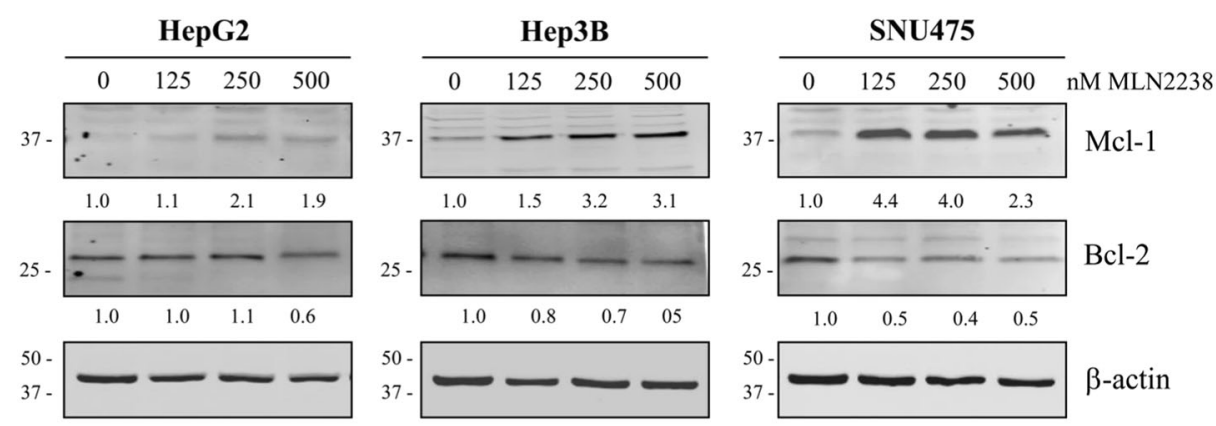

B
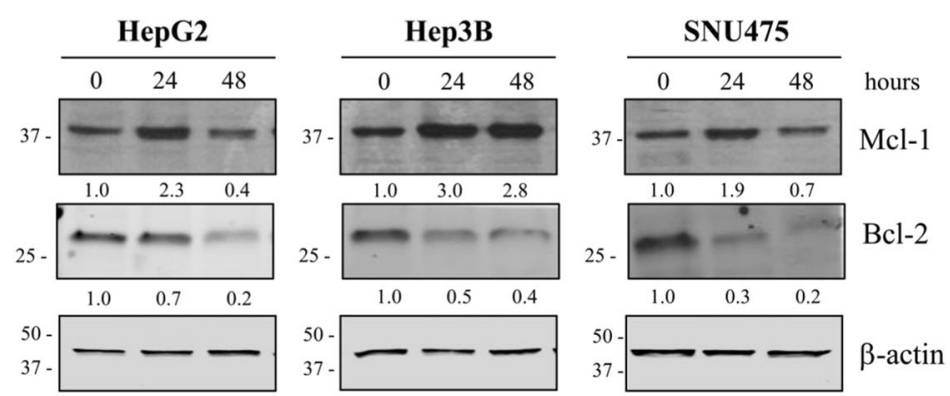

C
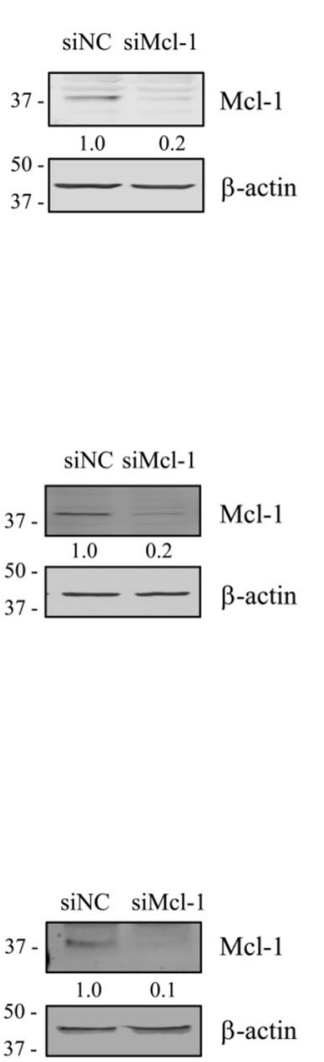

\section{HepG2}

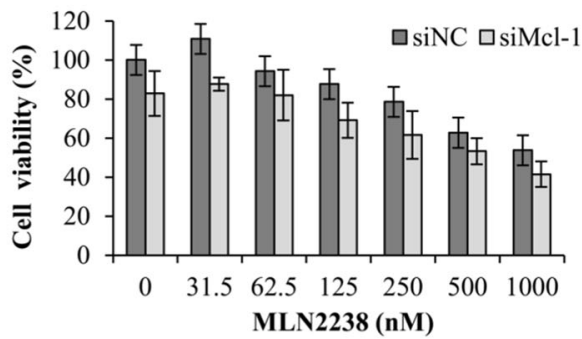

\section{Hер3B}

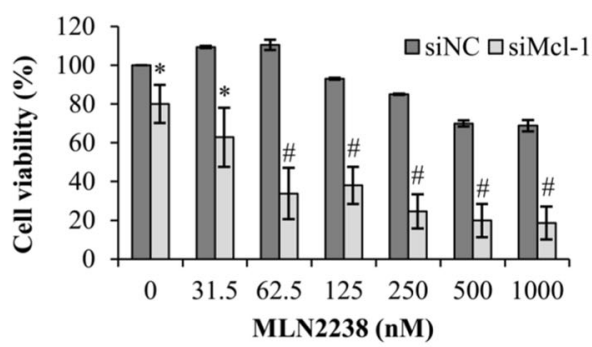

\section{SNU475}

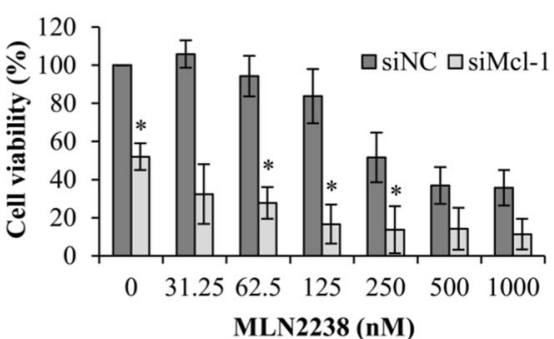

D

Hер3B

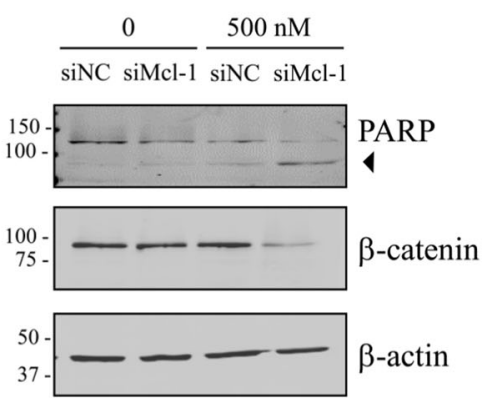

Fig. 5 (See legend on next page.) 
Fig. 5 MLN2238 treatment regulates expression of anti-apoptotic proteins $\mathrm{Mcl}-1$ and $\mathrm{Bcl}-2$, and $\mathbf{M c l}-\mathbf{1}$ knockdown sensitizes $\mathrm{HCC}$ cells to MLN2238-mediated cell death. Dose- $\mathbf{a}$ and time-dependent $\mathbf{b}$ effects of MLN2238 treatment on Mcl-1 and Bcl-2 expression determined by western blot analysis. a Cells exposed to the specified MLN2238 concentrations for $24 \mathrm{~h}$. b Cells treated with $500 \mathrm{nM}$ of MLN2238 for 24 and $48 \mathrm{~h}$. c Left panels, Mcl-1 expression levels after $72 \mathrm{~h}$ of transfection with Mcl-1 siRNA (siMcl-1) in cells compared with cells transfected with control siRNA (siNC). Right panels, viability of cells transfected with Mcl-1 siRNA (siMcl-1) after treatment with the indicated MLN2238 concentrations for $24 \mathrm{~h}$. $\mathbf{d}$ Representative western blotting of PARP and $\beta$-catenin levels expressed in Hep3B cells transfected with Mcl-1 siRNA (siMcl-1) or control siRNA (siNC) after $24 \mathrm{~h}$ of treatment with $500 \mathrm{nM}$ of MLN2238. The $85 \mathrm{kDa}$ form of PARP is indicated by an arrowhead. ${ }^{*} P<0.05 \mathrm{MLN} 2238 \mathrm{vs}$. control; ${ }^{\#} P<0.005$ MLN2238 vs. control

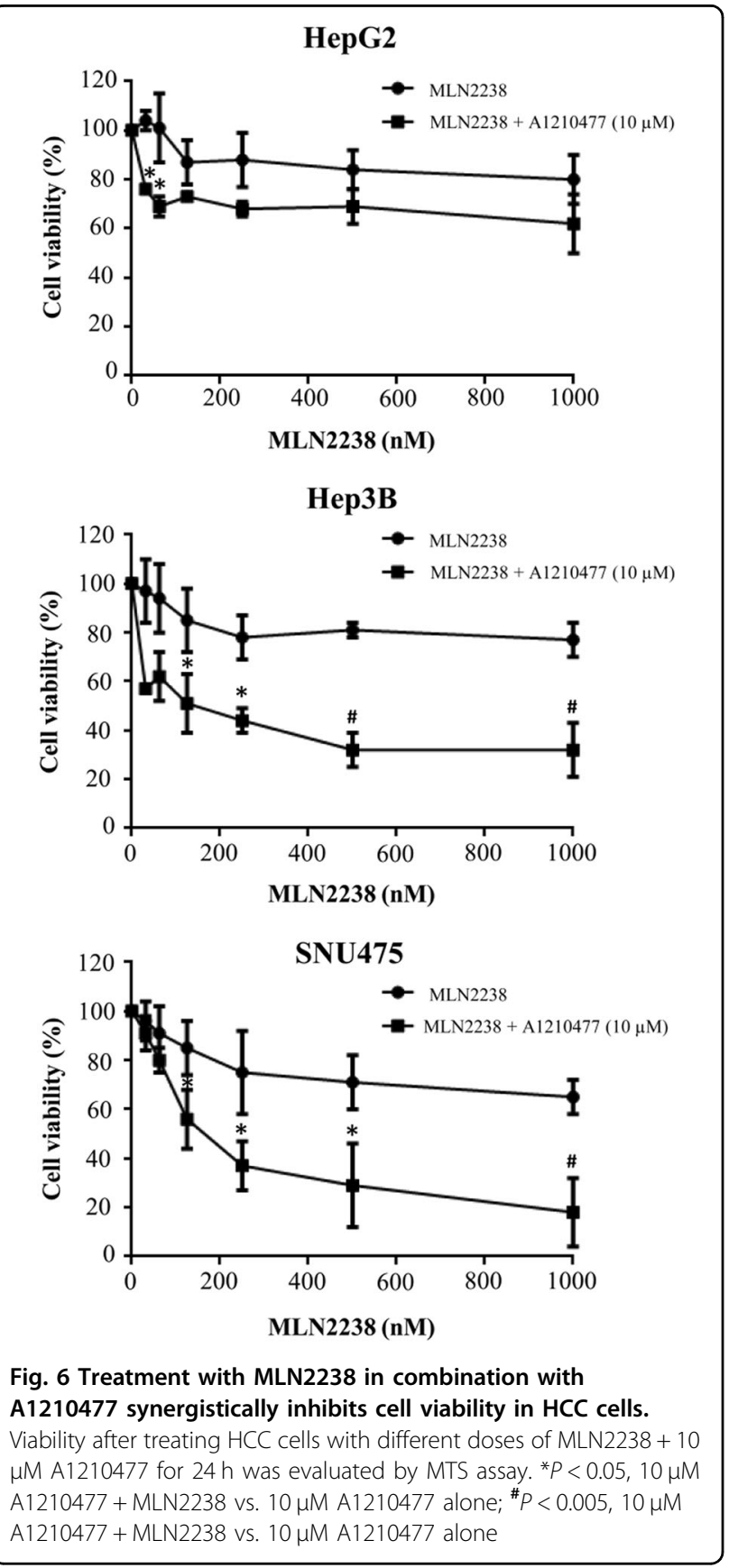

osteosarcoma $^{18}$, colon adenocarcinoma ${ }^{19}$, melanoma $^{20}$, and neuroblastoma cells ${ }^{21}$ in vitro and in vivo, using animal models.

Here, we demonstrated the potent antitumor effects of MNL2238 in HCC in both in vitro as well as in vivo models. To our knowledge, this is the first study assessing the use of the next-generation proteasome inhibitor MLN2238 in HCC.

Consistent with studies by other authors using different proteasome inhibitors, we showed that the cytotoxic effects of MLN2238-induced ER stress, apoptosis and cell cycle arrest at the G2/M phase, with upregulated p21 and p27 proteins ${ }^{18-20,22,28}$.

However, although the $\mathrm{IC}_{50}$ values of MLN2238 in Hep3B cells were lower than in the other two cell lines, the apoptotic response (in terms of PARP cleavage) to MLN2238 was delayed in time. These differences might be owing to different characteristics of differentiation, genetic defects, different ethnic origins, and to the biological behavior of these cell lines ${ }^{25,31}$, which are reflected in the tumor heterogeneity characterizing primary HCC. As an example: HepG2 cells carry a wild-type $p 53$ gene, Hep3B cells are $p 53$-null and SNU475 cells carry the mutated $p 53$ gene. Interestingly, a recent study, by Dabiri et al. ${ }^{32}$, showed that $p 53$-null colorectal cancer cells were transiently resistant, in the first $24 \mathrm{~h}$, to the proteasome inhibitor bortezomib, whereas becoming responsive after 48 or $72 \mathrm{~h}$ of treatment, when the oncosuppressor isoform of p73, TAp73, translocated and accumulated in the nuclei of treated cells. On the other hand, KD of $p 73$ in p53-null cells significantly prolonged the time of resistance to bortezomib. These results suggest that TAp73 was responsible for the delayed pro-apoptotic effects of bortezomib in cells lacking functional $\mathrm{p} 53^{32}$. Therefore, although we did not analyze the role of p73 during MLN2238 treatment in Hep3B cells, it could be hypothesized that a mechanism similar to those described by Dabiri et al., could explain the transient MLN2238 resistance observed in these cells. This interesting aspect needs further investigation and could be clarified by future studies.

We observed that the expression of Mcl-1, an antiapoptotic protein, was upregulated upon treatment with 
Table 2 MLN2238 in combination with $10 \mu \mathrm{M}$ A1210477 elicited synergistic inhibition of cell viability in HCC cells after $24 \mathrm{~h}$ of treatment

\begin{tabular}{llll}
\hline & $\begin{array}{l}\text { HepG2 } \\
\text { A1210477 }\end{array}$ & $\begin{array}{l}\text { Hep3B } \\
\text { A1210477 }\end{array}$ & $\begin{array}{l}\text { SNU475 } \\
\text { A1210477 }\end{array}$ \\
\hline MLN2238 (nM) & & & \\
31.25 & 0.703 & 0.543 & 1.030 \\
62.5 & 0.572 & 0.605 & 0.659 \\
125 & 0.754 & 0.524 & 0.368 \\
250 & 0.784 & 0.490 & 0.268 \\
500 & 1.129 & 0.414 & 0.258 \\
1000 & 1.453 & 0.456 & 0.209 \\
\hline
\end{tabular}

The combination index $(\mathrm{Cl})$ values are indicated. CalcuSyn software was used to calculate the $\mathrm{Cl}$, where a $\mathrm{Cl}<1$ indicated synergy, 1 indicated an additive effect and $>1$ indicated antagonism

MLN2238 in Hep3B cells after 24 h, and it also remained high at $48 \mathrm{~h}$ post-treatment, whereas expression declined at $48 \mathrm{~h}$ in the other two cell lines. It has been described that Mcl-1 accumulates as an undesired effect after exposure to proteasome inhibitors, and in addition, its expression decreases inhibitor efficacy ${ }^{33,34}$. Moreover, Mcl-1 expression continues in cells that have already undergone apoptotic response and is downregulated only at late time points after treatment ${ }^{33}$. This observation prompted us to assess the functional role of Mcl-1 in the apoptotic resistance to MLN2238 in Hep3B cells, especially considering that Mcl-1 has a pivotal role in $\mathrm{HCC}$. Mcl-1 expression is higher in human HCC tissue than in the adjacent non-tumor liver ${ }^{35,36}$, and it also protects HCC cells against the drug-induced apoptosis of chemotherapeutic drugs ${ }^{35,37}$.

Here, we demonstrated that Mcl-1 KD increased HCC cell sensitivity to MLN2238 and shortened the apoptotic response timing of HCC cells. In addition, we presented a novel strategy to enhance the efficacy of MLN2238 in $\mathrm{HCC}$ via modulation of Mcl-1 activity by pharmacological inhibition, using the small molecule Mcl-1 inhibitor A1210477. Our results demonstrate that combined treatment with MLN2238 and A1210477 represents a novel strategy for inducing synergistic inhibitory effects on cell viability in HCC cells. These data are consistent with results obtained by others using different proteasome inhibitors in various tumor types ${ }^{33,38}$, including MLN2238 39.

Therefore, although our study demonstrated that MLN2238 is cytotoxic to HCC cells, potential mechanisms of chemoresistance should be taken into consideration, owing to Mcl-1 upregulation. However, as we have demonstrated here, this could be overcome by a combination strategy, using a pharmacological approach to inhibit Mcl-1 with small molecule inhibitors.

In conclusion, our findings suggest that proteasome inhibitors are promising drugs to tackle HCC and justify further investigation and clinical validation.

\section{Materials and methods}

\section{Cell lines, cell culture, and reagents}

The human HCC cell lines HepG2, Hep3B, and SNU475 were acquired from the American Type Culture Collection (ATCC) (HB-8065, HB-8064, and CRL-2236, respectively) and were maintained as previously described $^{40}$. The cell lines were authenticated using short tandem repeat profiling (BMR Genomics, Padua, Italy). MLN2238, purchased from Selleck Chemicals (Houston, TX, USA), and A1210477, from Active Biochem (Bonn, Germany) were dissolved in dimethyl sulfoxide (DMSO).

\section{Cell viability and proliferation assays}

A total of $3 \times 10^{3}$ cells were added to 96 -well plates and after $24 \mathrm{~h}$ were exposed to varying doses of MLN2238 alone, or combined with a subtoxic dose $(10 \mu \mathrm{M})$ of Mcl-1 inhibitor A1210477. MTS assay was used to evaluate cell viability (see previous description) ${ }^{41}$. Data were recorded as a percentage of absorbance, comparing treated cells with controls (vehicle alone), and values expressed as the mean \pm standard deviation (S.D.) of three experiments, each performed in triplicate.

To evaluate eventual effects of MLN2238 on cell proliferation, the incorporation of BrdU into DNA was measured by a colorimetric assay (Roche Diagnostics $\mathrm{GmbH}$, Mannheim, Germany), as previously described ${ }^{40}$. Data are reported as the percentage of BrdU incorporation in treated cells compared with control cells. Values are reported as the mean \pm S.D. of three experiments performed in triplicate.

\section{Cell cycle and apoptosis analyses by flow cytometry}

HepG2 $\left(6 \times 10^{5}\right)$, Hep3B $\left(6 \times 10^{5}\right)$, and SNU475 $(4 \times$ $10^{5}$ ) cells were grown on $60-\mathrm{mm}$ tissue culture dishes. At $24 \mathrm{~h}$, the cells were exposed to MLN2238, and after $24 \mathrm{~h}$ flow cytometry was used for analyses (Becton Dickinson, Mountain View, CA, USA), performed as previously described $^{40}$. The annexin V-FITC apoptosis kit (Dojindo Laboratories, Munich, Germany) was used to detect apoptosis, as previously described ${ }^{42}$. Results are presented as a percentage. The values indicated are the mean \pm S.D. of two distinct experiments performed in triplicate.

\section{Caspase-3/7 activity assays}

A total of $3 \times 10^{3}$ HepG2, Hep3B, and SNU475 cells were distributed into 96-well plates. After $24 \mathrm{~h}$, cells received 250 and $500 \mathrm{nM}$ of MLN2238, and after an 

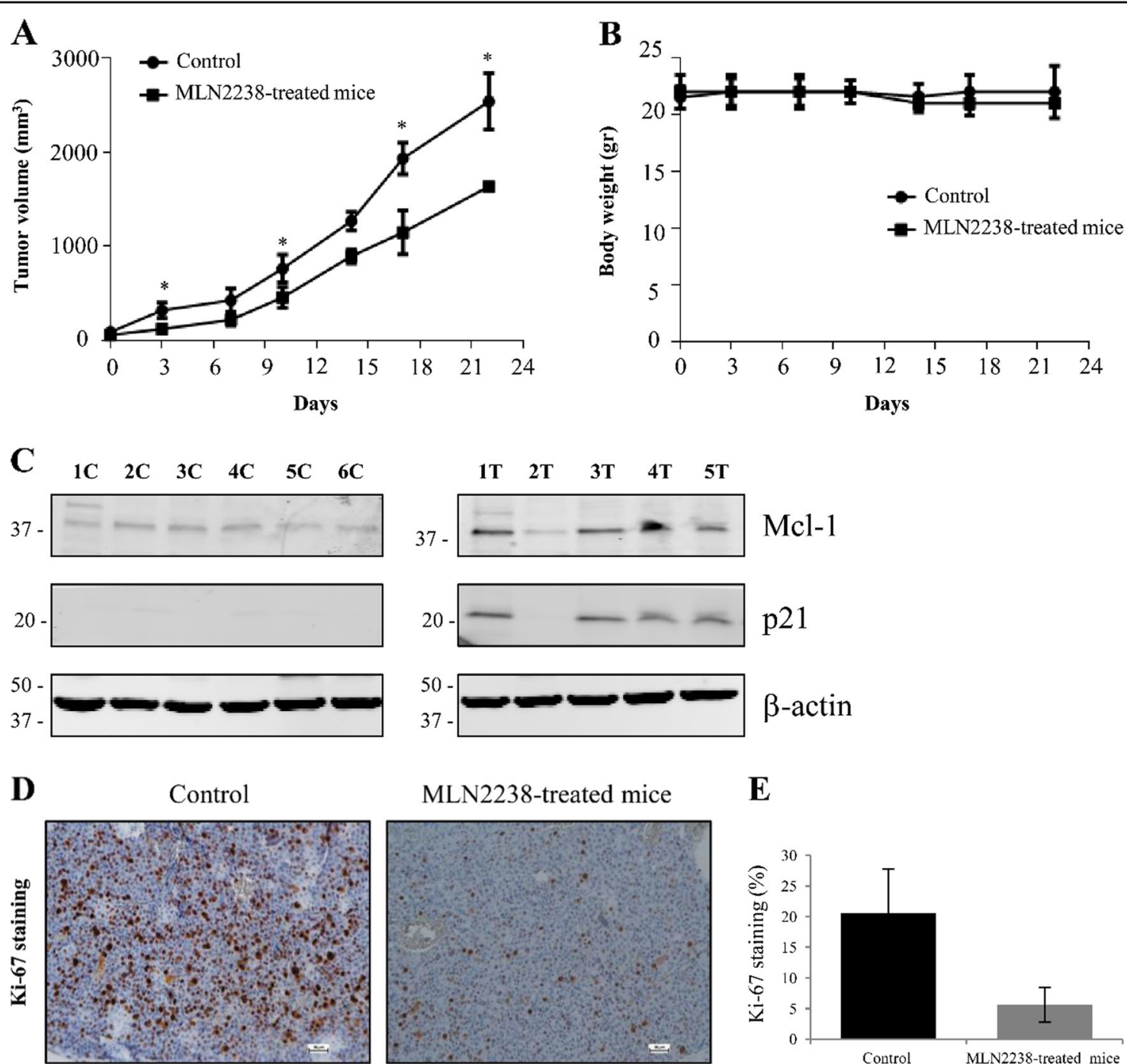

MLN2238-treated mice

$\mathbf{E}$
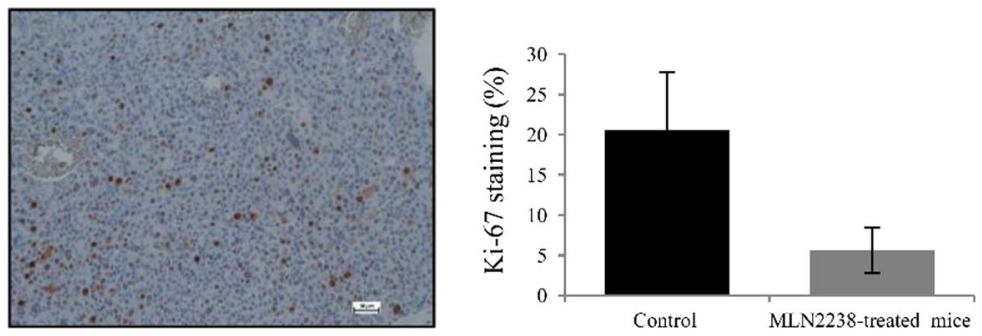

Fig. 7 MLN2238 inhibits tumor growth in vivo. a Effect of MLN2238 on tumor development. A comparison was made between the tumor growth curve of MLN2238-treated mice $(11 \mathrm{mg} / \mathrm{kg})$ and that of control mice receiving only vehicle as treatment, ${ }^{*} P<0.05$. $\mathbf{b}$ Analysis of body weight alterations. Animals were weighed two times/week and the data plotted in the graphs. c Representative immunoblotting of Mcl-1 and p21 expression levels in mice receiving only vehicle treatment (control: 1 C, 2C, 3C, 4C, 5 C, and 6C) and mice treated with MLN2238 (1 T, 2 T, 3 T, 4 T and $5 \mathrm{~T}$ ). $\mathbf{d}$ Immunohistochemical staining of the Ki-67 proliferation marker in the control and MLN2238-treated mice (scale bar $=50 \mu \mathrm{m}$ ). e Data indicate the number of positive cells and are expressed as the means \pm S.D. of five different fields in three sections of tumors from the control and the MLN2238-treated mice

additional $24 \mathrm{~h}$ the caspase-3/7 activities were recorded with the Caspase-Glo 3/7 Assay (Promega), following the manufacturers' instructions. Results are given as arbitrary units, indicating the mean \pm S.D. of two separate experiments, each performed in duplicate.

\section{siRNA transfection}

For siRNA transfection, $3 \times 10^{5}$ Hep3B and HepG2 cells, and $1.8 \times 10^{5}$ cells SNU475 cells were distributed into 6-well plates, containing culture medium without antibiotics. At $24 \mathrm{~h}$, this was substituted with fresh culture medium and $50 \mathrm{nmol} / \mathrm{l}$ of Mcl-1 siRNA (siMcl-1) was used to transfect cells. Control cell transfection was performed with a Negative Control siRNA (siNC). Transfections were carried out with Lipofectamine RNAiMax (Invitrogen, Carlsbad, CA, USA), following the manufacturers' instructions. siMcl-1 (SI02781205) and siNC (1027281) were acquired from QIAGEN (Germantown, MD, USA). After $24 \mathrm{~h}$ of transfection, cells were detached and seeded in 96-well plates or in $60-\mathrm{mm}$ plates in preparation for MTS assay and for protein extraction, respectively. 


\section{Western blotting}

RIPA buffer (Cell Signaling Technologies Inc., Beverly, MA, USA) was used to obtain cell lysates, and western blotting was performed as reported previously ${ }^{41}$. Primary antibodies against $\beta$-actin were obtained from SIGMA (Milan, Italy), Mcl-1 was from Santa Cruz (Dallas, TX, USA) and PARP, p21Waf1/Cip1, p27 from Cell Signaling Technologies (Beverly, MA, USA), while $\beta$-catenin was from BD Transduction Laboratories (San Jose, CA, USA.). The relative expressions were calculated as the ratio of drug-treated samples vs. control (DMSO) and corrected using the quantified level of $\beta$-actin expression.

\section{RNA extraction, real-time, and semiquantitative PCR}

Total RNA was extracted using the TRIzol method and $1 \mu \mathrm{g}$ of RNA was used for reverse transcription to generate cDNA using the QuantiNova Reverse Transcription Kit (QIAGEN), following the instructions of the manufacturer.

Quantitative Real-time PCR was analyzed using the QuantiNova SYBR Green PCR Kit (QIAGEN) and QuantiTect primers specific for Mcl-1 (QT00094122), NUPR1 (QT00088382), CHOP (QT00082278), GRP78 (QT00096404), TRB3 (QT00088543), and $\beta$-actin (QT00095431). Data are expressed as the relative mRNA expression level of the different genes in treated cells compared with control cells. Values given are the mean \pm S.D. of three different experiments performed in triplicate.

Semiquantitative PCR for the detection of XBP1 transcripts was performed using the following primers: $5^{\prime}$ CCTTGTAGTTGAGAACCAGG-3' and $3^{\prime}$-GGGGC TTGGTATATATGTGG-3' for XBP1 and $5^{\prime}$-CACCACACCTTCTACAATGAGC-3' ${ }^{\prime}$ and $5^{\prime}$-GAGGATCTTCATGAGGTAGTCAGTC- $3^{\prime}$ for $\beta$-actin, used as an internal control. The following programs were used to perform PCR reactions: $94^{\circ} \mathrm{C}(5 \mathrm{~min})$, then $94^{\circ} \mathrm{C}(30 \mathrm{sec})$, $57^{\circ} \mathrm{C}(30 \mathrm{sec})$ in the case of XBP1, and in the case of $\beta$ actin $60^{\circ} \mathrm{C}(30 \mathrm{sec})$, then $72{ }^{\circ} \mathrm{C}(30 \mathrm{sec})$, and a final elongation step at $72{ }^{\circ} \mathrm{C}(10 \mathrm{~min})$. Electrophoresis on agarose gel was performed to analyze amplified PCR products.

\section{In vivo studies}

For the in vivo studies, MLN2238 was dissolved in 5\% 2hydroxypropyl- $\beta$-cyclodextrin at $1 \mathrm{mg} / \mathrm{ml}$ concentration. Female athymic nude mice (Fox1 nu/nu) 4 weeks of age were acquired (Envigo, Udine, Italy). Animals were left to acclimatize for 1 week. An inoculation of $10 \times 10^{6} \mathrm{Hep} 3 \mathrm{~B}$ cells in $200 \mu \mathrm{l}$ of culture medium was made in the flank of the animal. When tumors reached the size of $150 \mathrm{~mm}^{3}$, the mice were randomly assigned to two groups of six animals each, receiving: $5 \%$ solution of 2 -hydroxypropyl$\beta$-cyclodextrin, two times/week by oral gavage in the control group (C) and $11 \mathrm{mg} / \mathrm{kg}$ of MLN2238, two times/ week by oral gavage, in the treated MLN2238 group (T). Volumes of tumors and body weight were documented (see previous report) $^{41}$.

After harvesting, each tumor was divided in half. One part was fixed in formalin and used for immunohistochemistry analysis, whereas the other was frozen in liquid nitrogen and stored at $-80^{\circ} \mathrm{C}$ for western blotting. All the procedures were performed abiding by institutional guidelines, which comply with national and international laws and policies. Authorization for the study was obtained from the Italian Ministry of Health (no. 1187/2015-PR).

\section{Immunohistochemistry analysis}

Immunohistochemical analysis was performed as reported previously ${ }^{39}$. To assess the proliferative index, nuclear antigen Ki-67 staining assay was carried out using a rabbit monoclonal antibody for Ki-67 (1:100) (Biocare Medical, CRM325). Expression level of Ki-67 was quantified as previously described ${ }^{40}$.

\section{Statistical analysis}

Student's $t$-test (two-tailed) was used for the statistical analysis. The statistical significance criterion was $p<0.05$. To determine the synergistic effect, data analysis was performed using CalcuSyn Version 2.0 software (Biosoft, Cambridge, UK). CI $<1$ indicated synergy, $\sim 1$ an additive effect and $>1$ antagonism. $\mathrm{IC}_{50}$ was calculated by linear regression with the GraphPad Prism 6 software (GraphPad Software Inc., La Jolla, CA, USA).

\section{Acknowledgements}

This work was supported in part by Associazione Italiana per la Ricerca sul Cancro (AIRC; project no. 18394).

\section{Author details}

${ }^{1}$ Institute of Biomedicine and Molecular Immunology "Alberto Monroy", National Research Council (CNR), Palermo, Italy. ${ }^{2}$ Istituto Zooprofilattico Sperimentale della Sicilia "A. Mirri", Histopathology and Immunohistochemistry Laboratory, Palermo, Italy. ${ }^{3}$ Biomedical Department of Internal Medicine and Specialties, University of Palermo, Palermo, Italy

Conflict of interest

The authors declare that they have no conflict of interest.

Received: 15 August 2017 Revised: 17 November 2017 Accepted: 30 November 2017

Published online: 18 January 2018

\footnotetext{
References

1. Torrecilla, S. \& Llovet, J. M. New molecular therapies for hepatocellular carcinoma. Clin. Res. Hepatol. Gastroenterol. 39, 80-85 (2015).

2. Curran, M. P. \& McKeage, K. Bortezomib: a review of its use in patients with multiple myeloma. Drugs 69, 859-888 (2009).

3. O'Connor, O. A. et al. Phase II clinical experience with the novel proteasome inhibitor bortezomib in patients with indolent non-Hodgkin's lymphoma and mantle cell lymphoma. J. Clin. Oncol. 23, 676-684 (2005).
} 
4. Lee, A. H., Iwakoshi, N. N., Anderson, K. C. \& Glimcher, L. H. Proteasome inhibitors disrupt the unfolded protein response in myeloma cells. Proc. Natl. Acad. Sci. USA 100, 9946-9951 (2003).

5. Jiang, H. Y. \& Wek, R. C. Phosphorylation of the alpha-subunit of the eukaryotic initiation factor-2 (elF2alpha) reduces protein synthesis and enhances apoptosis in response to proteasome inhibition. J. Biol. Chem. 280, 14189-14202 (2005).

6. Bao, W., Gu, Y., Ta, L., Wang, K. \& Xu, Z. Induction of autophagy by the MG-132 proteasome inhibitor is associated with endoplasmic reticulum stress in MCF7 cells. Mol. Med. Rep. 13, 796-804 (2016).

7. Ri, M. Endoplasmic-reticulum stress pathway-associated mechanisms of action of proteasome inhibitors in multiple myeloma. Int. J. Hematol. 104, 273-280 (2016).

8. Hsu, S. M. et al. Proteasome inhibitor bortezomib suppresses nuclear factorkappa B activation and ameliorates eye inflammation in experimental autoimmune uveitis. Mediat. Inflamm. 2015, 847373 (2015).

9. Brooks, A. D., Jacobsen, K. M., Li, W., Shanker, A. \& Sayers, T. J. Bortezomib sensitizes human renal cell carcinomas to TRAlL apoptosis through increased activation of caspase- 8 in the death-inducing signaling complex. Mol. Cancer Res. 8, 729-738 (2010).

10. Wu, Y. X., Yang, J. H. \& Saitsu, H. Bortezomib-resistance is associated with increased levels of proteasome subunits and apoptosis-avoidance. Oncotarget 7, 77622-77634 (2016)

11. Hui, B. et al. Proteasome inhibitor interacts synergistically with autophagy inhibitor to suppress proliferation and induce apoptosis in hepatocellular carcinoma. Cancer 118, 5560-5571 (2012).

12. Saeki, I. et al. Bortezomib induces tumor-specific cell death and growth inhibition in hepatocellular carcinoma and improves liver fibrosis. J. Gastroenterol. 48, 738-750 (2012).

13. Kim, G. P. et al. An international, multicenter phase ॥ trial of bortezomib in patients with hepatocellular carcinoma. Invest. New. Drugs 30, 387-394 (2012).

14. Chen, K. F. et al. Down-regulation of phospho-Akt is a major molecular determinant of bortezomib-induced apoptosis in hepatocellular carcinoma cells. Cancer Res. 68, 6698-6707 (2008).

15. Kupperman, E. et al. Evaluation of the proteasome inhibitor MLN9708 in preclinical models of human cancer. Cancer Res. 70, 1970-1980 (2010).

16. Suzuki, $K$. et al. Phase 1 study of ixazomib alone or combined with lenalidomide-dexamethasone in Japanese patients with relapsed/refractory multiple myeloma. Int. J. Hematol. 105, 445-452 (2017).

17. Moreau, P. et al. Oral ixazomib, lenalidomide, and dexamethasone for multiple myeloma. N. Engl. J. Med. 374, 1621-1634 (2016).

18. Liu, R. et al. A new perspective for osteosarcoma therapy: proteasome inhibition by MLN9708/2238 successfully induces apoptosis and cell cycle arres and attenuates the invasion ability of osteosarcoma cells in vitro. Cell Physiol. Biochem. 2, 451-465 (2017).

19. Engür, S. \& Dikmen, M. The evaluation of the anti-cancer activity of ixazomib on Caco2 colon solid tumor cells, comparison with bortezomib. Acta Clin. Belg. 22, 1-8 (2017)

20. Suarez-Kelly, L. P. et al. The combination of MLN2238 (ixazomib) with interferon-alpha results in enhanced cell death in melanoma. Oncotarget 7, 81172-81186 (2016)

21. Li, H. et al. Novel proteasome inhibitor ixazomib sensitizes neuroblastoma cells to doxorubicin treatment. Sci. Rep. 30, 34397 (2016).
22. Chauhan, D. et al. In vitro and in vivo selective antitumor activity of a nove orally bioavailable proteasome inhibitor MLN9708 against multiple myeloma cells. Clin. Cancer Res. 17, 5311-5321 (2011).

23. Wei, $X$. et al. MLN2238 synergizes BH3 mimetic ABT-263 in castration-resistant prostate cancer cells by induction of NOXA. Tumour Biol. 35, 10213-10221 (2014).

24. Fan, F. et al. Targeting Mcl-1 for multiple myeloma (MM) therapy: druginduced generation of $\mathrm{Mcl}-1$ fragment $\mathrm{MCl}-1$ triggers $\mathrm{MM}$ cell death via c-Jun upregulation. Cancer Lett. 343, 286-294 (2014).

25. Cervello, M. et al. Induction of apoptosis by the proteasome inhibitor MG132 in human HCC cells: Possible correlation with specific caspase-dependent cleavage of beta-catenin and inhibition of beta-catenin-mediated transactivation. Int. J. Mol. Med. 13, 741-748 (2004).

26. Obeng, E. A. et al. Proteasome inhibitors induce a terminal unfolded protein response in multiple myeloma cells. Blood 107, 4907-4916 (2006).

27. Chauhan, D. et al. In vitro and in vivo selective antitumor activity of a novel orally bioavailable proteasome inhibitor MLN9708 against multiple myeloma cells. Clin. Cancer Res. 17, 5311-5321 (2011).

28. Kroiss, M., Sbiera, S., Kendl, S., Kurlbaum, M. \& Fassnacht, M. Drug synergism of proteasome inhibitors and mitotane by complementary activation of ER stress in adrenocortical carcinoma cells. Horm. Cancer 7, 345-355 (2016).

29. Emma, M. R. et al. NUPR1, a new target in liver cancer: implication in controlling cell growth, migration, invasion and sorafenib resistance. Cell Death Dis. 7, e2269 (2016).

30. Muz, B. et al. Spotlight on ixazomib: potential in the treatment of multiple myeloma. Drug Des. Devel Ther. 10, 217-226 (2016).

31. Qiu, G. H. et al. Distinctive pharmacological differences between liver cancer cell lines HepG2 and Hep3B. Cytotechnology 67, 1-12 (2015).

32. Dabiri, Y. et al. The essential role of TAp73 in bortezomib-induced apoptosis in p53-deficient colorectal cancer cells. Sci. Rep. 7, 5423 (2017)

33. Nencioni, A. et al. Evidence for a protective role of $\mathrm{Mcl}-1$ in proteasome inhibitor-induced apoptosis. Blood 105, 3255-3262 (2005).

34. Wolter, K. G. et al. Therapeutic window for melanoma treatment provided by selective effects of the proteasome on Bcl-2 proteins. Cell. Death. Differ. 14, 1605-1616 (2007)

35. Yu, Q., Liu, Z. Y., Chen, Q. \& Lin, J. S. Mcl-1 as a potential therapeutic target for human hepatocelluar carcinoma. J. Huazhong. Univ. Sci. Technol. Med. Sci. 36 494-500 (2016)

36. Sieghart, W. et al. Mcl-1 overexpression in hepatocellular carcinoma: a potential target for antisense therapy. J. Hepatol. 44, 151-157 (2006).

37. Fleischer, B. et al. Mcl-1 is an anti-apoptotic factor for human hepatocellular carcinoma. Int. J. Oncol. 28, 25-32 (2006).

38. Zhang, S. D., Shan, L., Li, W., Li, H. L. \& Zhang, W. D. Isochamaejasmin induces apoptosis in leukemia cells through inhibiting Bcl-2 family proteins. Chin. J. Nat. Med 13, 660-666 (2015).

39. Yang, L. et al. BH3 mimetic ABT-737 sensitizes colorectal cancer cells to ixazomib through MCL-1 downregulation and autophagy inhibition. Am. J. Cancer Res. 6, 1345-1357 (2016).

40. Augello, G. et al. A PTEN inhibitor displays preclinical activity against hepatocarcinoma cells. Cell Cycle 15, 573-583 (2016).

41. Cusimano, A. et al. Cytotoxic activity of the novel small molecule AKT inhibitor SC66 in hepatocellular carcinoma cells. Oncotarget 6, 1707-1722 (2015).

42. Cusimano, A. et al. Oleocanthal exerts antitumor effects on human liver and colon cancer cells through ROS generation. Int. J. Oncol. 51, 533-544 (2017). 